\title{
A PRODUÇÃO DE UM ESPAÇO PÚBLICO E OS AGENTES PRODUTORES DA CIDADE: o caso do Lago Igapó em Londrina - PR
}

\author{
Carlos Alexandre de Bortolo ${ }^{1}$
}

\begin{abstract}
RESUMO
O trabalho apresenta algumas idéias e elementos para refletir acerca da produção do espaço da cidade. A priori devemos trabalhar com a reflexão sobre a natureza do espaço. Sendo este espaço um sistema de objetos cada vez mais artificiais, povoado por sistemas de ações igualmente imbuídos de artificialidade, e cada vez mais tendentes a fins estranhos ao lugar e a seus habitantes. As discussões aqui apresentadas relacionam com a produção dos espaços da cidade, aquela da produção e reprodução das relações sociais num determinado tempo e espaço e seus principais agentes produtores. Observando também a cidade como um produto/mercadoria para compreender como se processa as inúmeras formas de valorização do solo urbano. E como exemplo da produção do espaço urbano trazemos o Lago Igapó em Londrina-PR que se apresenta como uma área de lazer e que os espaços em seu entorno encontram-se valorizados devido as diversas formas de produção, ocupação e apropriação do espaço do Lago Igapó e suas adjacências. Destarte, buscamos refletir acerca do papel desempenhado pelos Estado, sendo um dos principais agentes produtores do espaço da cidade e fundamental para a compreensão da produção do espaço público do Lago Igapó em Londrina-PR.

Palavras Chave: Produção do espaço, Agentes Produtores, Estado, Lago Igapó, Londrina - PR.
\end{abstract}

\section{THE PRODUCTION OF A PUBLIC SPACE AND THE PRODUCERS AGENTS OF THE CITY: The case of Lago Igapó in Londrina - PR}

\begin{abstract}
The work presents some ideas and elements to reflect concerning the production of city spaces. A priori we must work with the reflection on the nature of the space. Being this space a system of artificial objects increasingly populated by systems of actions also steeped in artificiality, and increasingly designed for purposes other than the place and its inhabitants. The quarrels presented here relate to the production of city spaces, that the production and reproduction of social relations in a given time and space and its main producers. Also observing the city as a product / commodity to understand how the process of valuing the many forms of urban land. And as an example of production of urban space bring Lago Igapó in Londrina-PR area and the spaces around them are valued because of the different forms of production, occupation and ownership of the area of Lago Igapó and its adjacencies. Thus, we reflect on the role played by the State, being one of the main producers of city space and important to understanding the production of public space in the Lago Igapó in Londrina - PR.
\end{abstract}

Key Words: Production of space, Agents producers, State, Lago Igapó, Londrina - PR.

\footnotetext{
${ }^{1}$ Doutorando em Geografia pela Universidade Estadual de Maringá. E-mail: bortologeo@yahoo.com.br. Geo UERJ - Ano 12, nº. 21, v. 2, 2ºmestre de 2010. www.geouerj.uerj.br/ojs ISSN 1981-9021
} 


\section{INTRODUÇÃO}

Analisar o espaço urbano implica em entender que o processo de produção revela a indissociabilidade entre espaço e sociedade, na medida em que as relações sociais se materializam num território, significando dizer que, ao produzir sua vida, a sociedade produz e reproduz um espaço enquanto prática afirma (CARLOS, 2004).

Para a autora, que se fundamenta no pensamento de Henri Lefébvre, a noção de produção deve referir-se à produção do homem, às condições de vida da sociedade em seus múltiplos aspectos, ou seja, a noção de produção deve estar articulada inexoravelmente àquela de reprodução das relações sociais num determinado tempo e espaço.

Com o desenvolvimento deste estudo, nossos objetivos orientaram-se pela utilização de uma noção de refletir acerca da produção do espaço urbano de Londrina e o papel do Estado na produção do entorno do Lago igapó. Tal enfoque possibilitou realçar a dinâmica da estruturação e da produção das áreas do entorno do Lago Igapó, referindo-se aqui à disposição dos diversos usos de solo naquela porção do espaço urbano.

Outrossim, buscamos refletir acerca das principais formas e políticas de como o Estado vem atuando nos espaços da cidade e para isso, inserimos de uma forma breve a cidade de Londrina e um espaço público que foi sendo produzido e alterado pela atuação maciça do Estado e de alguns agentes produtores. Tal espaço é o Lago Igapó, um espaço público muito importante na configuração e organização das demais áreas da cidade de Londrina que vivem ou viveram a dinâmica do processo de produção do espaço urbano da cidade.

Processo esse que vai além da simples estruturação, reforçando a idéia de ruptura, movimento, reconstrução, sobreposição, articulação e interação socioespacial nos espaços da cidade. Trata-se de um processo que se expressa por meio das práticas cotidianas presentes no espaço público do Lago Igapó.

A atuação de diversos agentes produtores do espaço urbano denotam a primazia pela produção de uma cidade enquanto mercadoria (CARLOS, 2004) e funcionalista do ponto de vista socioeconômico, conseqüentemente, contraditório no que tange à realização do “direito à cidade” (LEFEBVRE, 1968).

Com isso, as cidades brasileiras na atualidade apresentam aos pesquisadores muitas questões, dentre as quais as diferentes formas e os agentes produtores da cidade e dos espaços públicos. Mas, além dessas diferentes formas de produção, o que mais representa refletir 
acerca desta temática é considerar tal espaço como um elemento chave na compreensão acerca da produção desse espaço e as inúmeras práticas estabelecidas no espaço da cidade pelos diferentes agentes produtores.

\section{CONSIDERAÇÕES SOBRE O ESPAÇO GEOGRÁFICO E A PRODUÇÃO DA CIDADE}

Ao longo de sua existência o homem promoveu transformações no espaço geográfico, seja por habitá-lo, explorá-lo, ou até mesmo usá-lo para satisfazer suas necessidades mais urgentes, como caçar, fazer fogo, morar, etc. Para Santos (1996), uma sociedade só se torna concreta por meio de seu espaço. A totalidade desse espaço é formada por instâncias ou estruturas (econômicas, jurídico-política e ideológica) e o espaço seria a quarta instância, colocando-se como uma estrutura subordinada e subordinante, um fator social e não apenas reflexo social.

A geografia poderia ser construída a partir da consideração do espaço

[...] Como um conjunto de fixos e fluxos. Os elementos fixos, fixados em cada lugar, permitem ações que modificam o próprio lugar, fluxos novos ou renovados que recriam as condições ambientais e as condições sociais, e redefinem cada lugar. Os fluxos são um resultado direto ou indireto das ações e atravessam ou se instalam nos fixos, modificando a sua significação e o seu valor, ao mesmo tempo em que, também, se modificam (SANTOS, 1996, p. 38).

Com isso o espaço, afirma Santos (1996), é formado por um conjunto indissociável, solidário e também contraditório de sistemas de objetos e sistemas de ações não considerados isoladamente, mas como o quadro único no qual a história se dá. No começo podíamos observar que era a natureza selvagem formada por objetos naturais que ao longo da história foram sendo substituídos por objetos fabricados, objetos técnicos, mecanizados, fazendo com que a natureza artificial tenda a funcionar como uma máquina (SANTOS, 1996, p. 39).

O espaço é hoje um sistema de objetos cada vez mais artificiais, povoado por sistemas de ações igualmente imbuídos de artificialidade, e cada vez mais tendentes a fins estranhos ao lugar e ao seus habitantes (SANTOS, 1996).

Com relação à ação humana, temos que entender que ela tende a transformar o meio natural em meio geográfico, isto é, em meio moldado pela intervenção do homem no decorrer da história. 
A Geografia possui uma árdua tarefa: relacionar os diversos acontecimentos no campo das relações homem/natureza e ao mesmo tempo se preparar pelo porvir. Os agentes são muitos e os lugares são os mais variados possíveis, contudo, há as rugosidades no espaço, como afirma Santos (1996).

O espaço não é homogêneo, mas é singular e específico a cada realidade vivida. O capitalismo não conseguiu implantar por completo formas, modos e maneiras de se obterem os espaços de modo que ficassem semelhantes e mais globais. As desigualdades são muitas e quando falamos em caos, não discutimos um fim, mas sim, no conflito e na desordem que trará enfim, uma nova ordem ou não.

Desta forma, é necessário pensar e compreender o espaço e, por conseguinte, a cidade e o urbano. Isso diz respeito ao comprometimento teórico com a teoria espacial a partir da abordagem que toma por conceito a produção do espaço, presente de forma efetiva no pensamento marxista a partir e por meio da obra de Henri Lefebvre (1976).

Sendo a Geografia uma ciência social e, como toda ciência social dedicada ao estudo da sociedade (SANTOS, 2002), a análise se assenta no campo científico mais propriamente concernente a essa ciência e às ciências parcelares dedicadas em alguma medida, ao estudo da dimensão espacial da sociedade, ainda que reconheça a preponderância da ciência geográfica nas análises atinentes ao espaço social.

Ao longo dos anos muitas têm sido as tentativas de conceituação do espaço levadas a cabo tanto pela Geografia quanto por outras ciências afins e mesmo pela Filosofia. Uma compreensão coerente do espaço traz em seu bojo a possibilidade de desvendar as contradições inerentes ao ser e fazer sociais, já que está mais do que provada à importância que tem o espaço na reprodução da sociedade.

Em La production de l'espace (2000), o objetivo de Lefebvre é a busca de uma teoria espacial unitária que englobe os vários campos no âmbito dos quais o espaço tem sido tratado pelos diversos domínios científicos e pela Filosofia, sobretudo no Ocidente.

A reflexão teórica sobre o espaço, em Lefebvre (2000), parte do princípio de que aquilo que pode ser reconhecido como espaço, na verdade, sempre foi tratado a partir de perspectivas de análise com enfoques diferentes, sem preocupação com uma possível unidade que pode ser agrupadas em três campos: um físico, relacionado, sobretudo, à dinâmica e às leis da natureza, do cosmos; um mental, referente à abstração e ao pensamento lógico formal; e um terceiro, social, ligado à organização e ao desenvolvimento das relações sociais. 
Assim, no ponto de vista de (LEFEBVRE, 2000, p. 459, tradução nossa, grifos do autor), “[...] em termos espaciais, têm-se: o espaço percebido, aquele da prática espacial; o espaço concebido, relacionado às representações do espaço; e o espaço vivido, referente aos espaços de representação”. Para o autor, essa tríade espacial jamais pode ser tomada como um modelo abstrato, distanciado da concretude da vida sob pena de perder sua força teórica.

O esforço de Lefebvre (2000) direciona-se, então, para alcançar um conhecimento propriamente do espaço, superando as análises que se focam mais sobre as coisas existentes no espaço ou as que se restringem apenas ao plano de um discurso espacial. Sem esse conhecimento, “[...] somos levados a transferir para o nível do discurso, da linguagem per se - isto é, o nível do espaço mental - uma larga porção dos atributos e 'propriedades’ daquilo que é, na verdade, o espaço social” (LEFEBVRE, 1991, p. 07, tradução nossa, grifos do autor).

Esse conhecimento do espaço só pode ser alcançado por uma análise que considere as três dimensões supracitadas de forma a reconhecer que tanto o espaço percebido quanto o concebido e o vivido são, fundamentalmente, o mesmo espaço tomado em dimensões de análise distintas.

Essas dimensões, no plano do cotidiano, porém, não se dissociam, mas têm igual importância para a vida em sociedade e incidem diretamente sobre ela. A teoria unitária espacial em Lefebvre (2000) consiste em compreender que o espaço é antes de tudo, social. Para a Geografia, como ciência dedicada à compreensão espacial da sociedade, essa afirmação implica considerar que as análises devem obrigatoriamente levar em conta a implicação social que têm quaisquer fenômenos de ordem espacial.

Essa acepção não implica forçosamente que as dimensões, física e mental, sejam desprivilegiadas na análise espacial, mas assevera que a dimensão social é a que engloba as demais na medida em que é nela que a vida social se revela.

Nesse sentido, a dialetização do espaço - entendido como uma mediação interativa entre as formas do ambiente construído, resultante da transformação da natureza e também a vida social que anima essas formas - é tanto mais necessária, já que, segundo Massey (2004), o espaço está num eterno processo de devir, nunca acabado e jamais fechado ou cíclico, sendo o domínio que permite a existência da multiplicidade e a coexistência de trajetórias diversas. A abertura possibilitada pela triplicidade impede que o espaço seja visto como um sistema 
dentro do qual tudo esteja previamente relacionado com tudo, como uma simultaneidade finalizada, cujas interconexões estejam desde sempre estabelecidas.

O espaço socialmente produzido caracteriza-se entre outros aspectos, pela diferenciação de suas formas, conteúdos, interações e as práticas espaciais. Essa diferenciação do espaço é em realidade, um reflexo e uma condição de e para as políticas públicas e empresariais, afirma Corrêa (2002).

No dizer de Santos (1996), a ciência geográfica caracteriza-se como uma ciência do espaço do homem. Conforme nos apresenta Corrêa (2002), é necessário pensarmos o espaço geográfico em sua multidimensionalidade, ou seja, como algo que é absoluto e relativo, “[...] descrito através de diversas metáforas, reflexo e condição social, experienciado de diversos modos, rico em simbolismos e campo de lutas” (CORRÊA, 2002, p.44).

Para Santos (1996),

O espaço seria um conjunto de objetos e de relações que se realizam sobre estes objetos; não entre estes especificamente, mas para as quais eles servem de intermediários. [...] O espaço é resultado da ação dos homens sobre o próprio espaço, intermediados pelos objetos, naturais e artificiais (SANTOS, 1996, p.71).

Esse mesmo autor faz referência a característica do movimento inerente ao espaço e destaca que o "[...] espaço é o resultado de um matrimônio ou um encontro, sagrado enquanto dura, entre a configuração territorial, a paisagem e a sociedade” (SANTOS, 1996, p.77).

Corrêa enfatiza a organização espacial como sendo o “[...] conjunto de objetos criados pelo homem e dispostos sobre a superfície da terra, sendo uma materialidade social” (CORRÊA, 1986).

Com base no exposto acima, podemos pensar no espaço como sendo uma totalidade que compreende objetos (naturais e artificiais), atores sociais, ações e conflitos que se interrelacionam e se realizam num constante movimento. Essa totalidade, por sua vez, é constituída pela ação do homem sobre o próprio espaço por intermédio de tais objetos e se materializa por via do território.

Com isso, passamos a compreender como as formas espaciais que são dadas num determinado momento podem conter muitas vezes os reflexos do passado ou de outras formas espaciais que se transformaram e vêm se transformando, por via de um constante movimento que se estabelece pelo intermédio das ações do homem. 
Assim, o espaço é o lócus de uma determinada organização de objetos relacionados entre si. Em vista disto, podemos dizer que ele não existe só, isoladamente, no vazio. Existe na medida em que contém objetos e, ao mesmo tempo é condição de existência deles.

\section{OS AGENTES PRODUTORES DO ESPAÇO URBANO}

As inúmeras transformações ocorridas na cidade em razão de determinações de ordem socioeconômica, ambiental, estética, lazer, entre outras; é tema de interesse de diversos pesquisadores, como de disciplinas que integram recortes analíticos que possibilitam o estudo da estruturação da cidade.

A urbanização contemporânea articula-se às dinâmicas do modo capitalista de produção, o qual direciona esse processo sob a perspectiva de uma economia política da urbanização compreendida conjuntamente com uma economia política da cidade. Por conta disso, a estruturação dos espaços urbanos e os objetos que os constituem não podem ser tomados, nem analisados, como simples objetos estruturantes da base material, tendo em vista que a produção do espaço urbano sob tais perspectivas os envolvem com os meios que caracterizam o ambiente construído, também se tornando meios de consumo urbano.

Esse referencial analítico do espaço urbano no qual nos fundamentamos teoricamente está embasado aqui na idéia de Carlos (2004), de que a análise espacial da cidade no que se refere ao processo de produção, revela a indissociabilidade entre espaço e sociedade, na medida em que as relações sociais se materializam num território material e concreto, o que significa dizer que ao produzir sua vida, a sociedade produz/reproduz um espaço enquanto prática (CARLOS, 2004, p. 14).

Para essa autora, fundamentada no pensamento lefebvriano, a noção de produção deve referir-se à produção do homem e às condições de vida da sociedade em seus múltiplos aspectos, ou seja, a noção de produção deve estar articulada inexoravelmente àquela de reprodução das relações sociais num determinado tempo e espaço.

“[...] É fundamental do ser humano o ato de criar, formar e produzir pelo próprio trabalho e sua atividade, sendo esta capacidade criadora de obras” (CARLOS, 2009, p. 75). Destarte, a noção de produção do espaço traz implícita a idéia de atividade como ação transformadora da sociedade modificando a natureza e impondo uma dinâmica que é em essência, social e histórica. 
O processo de produção do espaço contém como pressuposto a natureza, envolvendo um conjunto de elementos fundados na atividade humana produtora e transformadora.

Visto isso, o solo pode ser consumido em atividades produtivas ou para a habitação. Mas pode também ser direcionado especificamente por lapso de tempo para a especulação. Para este solo ser consumido ${ }^{\mathrm{i}}$, ele deve ser produzido para que possa aparecer no mercado como mercadoria.

Sposito (1990) apresenta que o mercado é importante porque condiciona (pela oferta e pela demanda) as razões da apropriação dos lotes urbanos por parte de consumidores e investidores porque não existe a capacidade de cada um destes produzir individualmente o solo.

Neste momento de nossa discussão devemos evidenciar que os promotores imobiliários que atuam na cidade de Londrina - PR e especificamente nas áreas do entorno do Lago Igapó planejam, monopolizam e criam o espaço urbano na medida em que orientam o tipo de classes que ocupará uma ou outra parcela do espaço. Temos que lembrar que uma das características fundamentais do processo de produção da cidade é a produção de um bem, fruto do processo social de trabalho enquanto processo de valorização.

Destarte, o espaço se apresenta como um produto social em constante processo de reprodução que se da mediante a reprodução das relações sociais, via divisão social do trabalho (CORRÊA, 1986).

Essa organização espacial da cidade capitalista se dá pelo conjunto de diferentes usos da terra; e se tratando de um produto social, entram em cena, vários agentes que de maneira complexa e distintas vão provocando constantemente um processo de reorganização espacial.

O espaço urbano capitalista - é fragmentado, articulado, reflexo, condicionante social, cheio de símbolos e campo de lutas - é um produto social, resultado de ações acumuladas no tempo, e engendradas por agentes que produzem e consomem espaço. São agentes sociais concretos, e não um mercado invisível ou processos aleatórios atuando sobre um espaço abstrato (CORRÊA, 2002, p.11).

Deste modo, Corrêa (2002) nos faz entender como se processa a produção da cidade, como ela é produzida e quais são os agentes encontrados. O autor apresenta esse espaço como um elemento fragmentado através de diferentes formas de usos que ao mesmo tempo deve ser 
empreendido de maneira articulada mantendo em cada uma das partes relações diversas umas com as outras.

Estas relações devem ser caracterizadas não apenas de formas visíveis como os meios de transporte, seus deslocamentos etc, mas sim, ocorre de um modo menos visível como, por exemplo, circulações de decisões, investimentos de capital, mais-valia, salários e juros afirma Corrêa (2002).

Desta forma, observando que o espaço urbano capitalista é fragmentado, articulado, reflexo, condicionante social, cheio de símbolos e campo de lutas, entendemos que ele deve ser empreendido como um produto social, resultado de ações acumuladas através do tempo e engendradas por agentes que produzem e consomem o espaço. Estes agentes sociais são concretos e suas ações são complexas, sendo estas ações derivadas da dinâmica de acumulação de capital e das necessidades multáveis da reprodução das relações de produção (CORRÊA, 2002).

Seguindo as idéias de Fresca (2002) devemos entender quem são os agentes sociais que produzem o espaço urbano londrinense. Ela ainda nos apresenta que

Trata-se de uma compreensão em termos amplos, isto é, como referência básica acerca dos agentes e das estratégias e ações concretas por eles desempenhadas. Isto ocorre porque na realidade, os agentes sociais com práticas e ações antagônicas podem unir-se em prol de objetos comuns que atendem seus interesses, bem como se pode encontrar na realidade (FRESCA, 2002, p. 249).

A sociedade urbana se anuncia e se projeta na vida recriando-a, compondo não só uma totalidade mais ampla, mas como aponta Henri Lefebvre (1999, p.16), transformando-se também em objeto.

O processo de reprodução espacial na cidade se realiza na articulação de três níveis: o político (que se revela na gestão política do espaço), o econômico (que produz o espaço como condição e produto da acumulação) e o social (que nos coloca diante das contradições geradas na prática socioespacial como plano da reprodução da vida). A articulação desses níveis se efetiva pela mediação do Estado, que organiza as relações sociais (e de produção) por meio da reprodução do espaço.

O modo de produção capitalista se reproduz superando barreiras ao seu desenvolvimento, resolvendo impasses; e nesse processo, o Estado aparece como instituição 
capaz de criar mecanismos que permitam resolver as contradições à realização da acumulação. Em seu contínuo processo de reprodução, o capital se depara com contradições que emergem da produção do espaço associada aos obstáculos criados pela existência da propriedade privada do solo urbano, na medida em que aparece como barreira à concretização da reprodução ampliada - nesse caso, só o Estado pode com suas estratégias, agir no sentido de eliminar ou atenuar as barreiras ao desenvolvimento da reprodução do capital. Aqui, os promotores imobiliários ganham importância, pois com sua ação junto ao Estado, criam concretamente formas capazes de permitir a continuidade do processo.

O que ocorre é que a terra (solo) torna-se mercadoria no espaço da cidade; nessa condição, ele é fragmentado e comercializado em lotes no mercado. É ai que a condição de propriedade privada de parcelas significativas da cidade entra em conflito com as necessidades da reprodução do capital, em especial nas áreas centrais da cidade, nesse caso o Estado intervém no processo de modo a liberar as áreas necessárias ao crescimento e o faz lançando mão de mecanismos legais que transformam a propriedade privada em propriedade de interesse público.

Assim, o choque produzido por estratégias diferenciadas no espaço entre o Estado e os promotores imobiliários, é atenuado em função de um acordo momentâneo e localizado entre dois segmentos diferenciados e com interesses divergentes da sociedade. O Estado intervém no sentido de eliminar as barreiras ao desenvolvimento continuado do capital, mas não elimina as contradições do processo de reprodução espacial: homogênea como imposição de sua ação e fragmentada pelas estratégias imobiliárias.

A gestão política impõe ao espaço uma racionalidade que se quer homogênea e que por meio de grandes investimentos muda superfícies imensas, passíveis de serem modificadas apenas pela interferência do Estado. O capital produz o espaço como condição (e produto) de sua reprodução, o Estado intervém por mecanismos de gestão que criam o espaço como meio de dominação e o setor financeiro utiliza-se da produção do espaço como meio de investimento para possíveis áreas de especulação imobiliária.

Conflituosamente há os interesses do cidadão, que vêem a cidade como condição da reprodução da vida. Nesse sentido os interesses em jogo entram em conflito no plano da prática socioespacial apontando o choque entre o espaço, que é produzido como valor de troca e o produzido como valor de uso, entre a dominação da troca e os modos de apropriação pelo 
uso. Desse modo, o espaço se reproduz como condição/produto da reprodução do capital e ao mesmo tempo como instrumento político vinculado ao Estado.

Nesse sentido, o movimento de transformação das cidades em mercadoria, em produtos para o mercado, situa-se na esfera estrutural do mercado imobiliário através de instrumentos das políticas público-privadas de promoção e venda das cidades.

A emergência da cidade-mercadoria sinaliza um novo patamar no processo de mercantilização do espaço, produto do desenvolvimento do mundo da mercadoria, do processo de internacionalização do capital na contemporaneidade. Tais processos estão imbricados nos processos históricos de acumulação do capital no urbano.

Um espaço próprio à fase atual do capitalismo vem sendo produzido, específico das sociedades urbanas dirigidas e dominadas por relações de produção capitalista, com a adaptação técnica do território, a renovação de infraestruturas de mobilidade e a construção de espaços e equipamentos seletivos voltados aos negócios, ao consumo e à habitação.

No entanto, observamos nas atuais circunstâncias que a atuação dos diversos grupos produtores do espaço urbano (CORRÊA, 2002) denota a primazia pela produção de uma cidade enquanto mercadoria (CARLOS, 2001) e funcional do ponto de vista socioeconômico, conseqüentemente contraditório no que tange à realização do “direito à cidade” (LEFEBVRE, 1991).

Por outro lado, observamos em curso a predominância da cidade como condição de reprodução do capital e dominação do Estado, ambas esvaziadas do sentido da vida humana (CARLOS, 2004). Em função das necessidades da reprodução e acumulação capitalista, presenciamos uma relação desigual e combinada de contraposição entre o público e privado na cidade. Entre interesses sociais de cunho coletivo e interesses econômicos de natureza individual e privada, prevalece o último.

Vários são os responsáveis pela evolução da estrutura urbana no tempo, analisá-los de forma detalhada seria tarefa por demais complexa e por esta razão, e sem descuidar da ação exercida por outros agentes modeladores do espaço, buscamos neste estudo dar uma maior atenção ao papel desempenhado pelo Estado, sendo este um dos agentes mais importantes e complexos de se entender quando se trata de tecer análises acerca da produção da cidade e do urbano. 


\section{O PAPEL DO ESTADO NA PRODUÇÃO DA CIDADE}

O Estado não tem uma participação neutra no contexto urbano, como pretende os modelos neoclássico-liberais. Embora ele também não deva ser concebido apenas como mero instrumento político ou como uma instituição estabelecida pelo capital, não há dúvida de que no cenário capitalista ele expressa o seu interesse. Daí é de se esperar que a ação pública venha contribuir efetivamente para a construção diferenciada do espaço, provendo as áreas de interesse do capital e das classes dominantes de benefícios que são negados às demais classes da sociedade.

Apesar de se constituir em agente distinto do capital, o papel do Estado no campo econômico tem sido o de garantir condições à reprodução do capital, fazendo concessões apenas quando estas se evidenciam necessárias, ou seja, para assegurar as condições mínimas de reprodução da força de trabalho ou quando as pressões dos “de baixo" se tornam irresistíveis.

Segundo Razente (1984) em alguns casos,

O Estado produz os bens e transfere ao capital privado a exploração dos serviços, o fato é que o Estado passa a ter no estágio monopolista, o controle da massa de capital alocada nas condições gerais da produção. O Estado irá intervir como produtor de mercadoria, consumidor, normatizador das relações de capital-trabalho, mantenedor de “ordem-social” (RAZENTE, 1984. p. 30).

Deste modo, o papel do Estado na atuação de produção dos espaços da cidade deve ser encarado em diversos momentos e situações. O Estado intervém de inúmeras maneiras, mas, sobretudo seguindo cinco principais vetores, afirma Razente:

O Estado e a Força de trabalho- Ele participa na reprodução de força de trabalho seguindo dois eixos principais: primeiro deles, dá-se no sentido de capacitar a força de trabalho, e com isso, reduzindo a participação do capitalista empregador. No segundo, visa promover uma série de condições necessárias à reprodução da força de trabalho e com isto diminuindo os custos de reprodução da mesma. São valores de uso nos quais o Estado vincula sua participação principalmente nas áreas de saúde, transporte, habitação e segurança social, que autores como Lojkine e Castells colocam como "bens coletivos".

O Estado Produtor- O Estado assume a produção de valores de troca, naquelas mercadorias que exigem o investimento de grandes capitais e onde a maturação dos investimentos é longa. Evita, assim, que estes setores entrem na determinação geral do lucro. De outra maneira, assume a produção de mercadorias nos setores considerados de "segurança nacional", Geo UERJ - Ano 12, nº. 21, v. 2, 2º semestre de 2010.

www.geouerj.uerj.br/ojs ISSN 1981-9021 
ou nas áreas consideradas vitais para o bom desempenho da economia, face à possibilidade de escassez de recursos.

O Estado Regulador- O Estado regulador pode tomar várias formas. Pode ser visto como regulador da força de trabalho, na medida em que institui um conjunto de normas que dizem respeito ao controle ou a reprodução da força de trabalho. Podem ser visualizados nas leis trabalhistas, no controle e instituição do piso salarial, na criação de fundos públicos, ou, até mesmo como regulador da "ordem social"

O Estado Empregador- em momentos de crise conjuntural, o sistema econômico, o Estado pode praticar políticas visando a manutenção dos níveis de emprego.

O Estado Planejador- servindo de atributo no estágio do capitalismo monopolista, atribuindo o Estado a propriedade de planejar a economia e o espaço através de um conjunto de normas ou mesmo de plenos gerais de desenvolvimento proporcionados para todo o espaço nacional (RAZENTE, 1984. p. 31).

Com isso o Estado se apresenta como gestor, produtor, regulador, empreendedor e planejador nos diferentes momentos de sua atuação na questão de produzir o espaço. Com essas rápidas transformações provocadas pela globalização econômica permite-se questionar como será a geografia resultante do processo de reorganização do capital, da revolução tecnológica em curso e de rearranjos na gestão pública.

Em um de seus trabalhos Abreu (2006), se apresenta na perspectiva de contribuir no estudo do papel do Estado para a evolução da estrutura urbana da cidade do Rio de Janeiro e de sua organização atual. Abreu (2006) aborda que segundo a visão do Estado, a ação decorreria única e exclusivamente da necessidade de coordenar decisões individuais de uma forma que fosse socialmente "ótima”, tanto do ponto de vista da eficiência como da equidade social. Desta forma, o Estado seria assim o grande mediador dos conflitos existentes no espaço e sua função principal seria resolvê-los de tal forma que a sociedade como um todo não fosse prejudicada (ABREU, 2006).

Corrêa (2002) ao discutir a ação do Estado como agente produtor do espaço urbano, deixa bem visível a complexidade e a variedade de possibilidades de sua atuação na organização da cidade, na medida em que tal agente social desempenha inúmeros papéis. $\mathrm{O}$ Estado pode ser um grande industrial, quando ele implanta uma indústria estatal; ele pode ser também um promotor fundiário, já que o Estado apresenta em seu controle as terras públicas; pode ser também um promotor imobiliário na medida em que ele proporciona habitações via órgãos como a Cohab, e também devido ser um ofertador de infraestrutura básica, responsável 
pela regulamentação e uso do solo é tido como alvo dos movimentos sociais que reivindicam serviços públicos.

O Estado desempenha dominantemente as atividades do tipo produtivo, isso significa dizer que o mesmo assume diretamente a tarefa da promoção imobiliária, por meio das agências públicas e em associação com sociedades habitacionais sem fins lucrativos e cooperativos habitacionais. Podemos com base no sistema implantado e montado nos anos de 1964 a 1986 no território nacional, com a implantação do Banco Nacional de Habitação (BNH), constituiu-se no Brasil um dinâmico mercado de acesso à casa própria, assentado sobre um sistema especializado no crédito habitacional.

Na produção do espaço urbano e na circulação da mercadoria "moradia”, estão envolvidos vários agentes, como o proprietário fundiário, o capital construtor, o incorporador, os agentes financeiros, os investidores finais, enfim, cada qual envolvido em circuitos específicos de valorização.

Conforme demonstra Ribeiro (2003), o capital incorporador acabou por se constituir no principal agente que comandou os processos de estruturação urbana no Brasil no período mais recente à medida que encabeça a condução desse processo ao impor novos padrões de produção de moradia - e de circulação - cuja marca maior é o processo de verticalização, subordinando outros agentes econômicos - sejam os proprietários fundiários, sejam as empresas de construção - à sua lógica de atuação.

O ramo da incorporação imobiliária é o elemento central nos processos que envolvem a produção e a circulação, uma vez que comanda as decisões que permitem a transformação do capital-dinheiro em mercadoria-moradia, que após circular, converte-se novamente em capital-dinheiro. Nos processos que envolvem a geração da renda fundiária urbana, as condições de valorização dos capitais via uso do solo urbano, ocorrem de forma particular, segundo o ramo de atividade. Assim, para o capital industrial, comercial e financeiro, a terra urbana tem por papel oferecer o acesso aos chamados efeitos úteis de aglomeração como meio de viabilizar a geração dos sobrelucros. De fato, podemos dizer que o espaço urbano é a materialização do sistema capitalista, onde a sua produção assim como a sua transformação, resultam da circulação do capital no seu ciclo de reprodução.

Tal fenômeno de produção é vísivel no espaço do entorno do Lago Igapó na cidade de Londrina, haja vista a valorização que tal área apresenta após a atuação de políticas públicas e incentivos privados para a produção de moradias para classes de alto poder aquisitivo. Esse 
processo ocorre ao longo do tempo devido a infraestrutura oferecida as áreas adjacentes do Lago Igapó como também na venda publicitária de que as incorporadoras e as construtoras vendem não apenas o lote e seu empreendimento mas sim, as mesmas vendem um "novo estilo de vida”.

Para os capitais vinculados ao ramo imobiliário, a localização é mais decisiva como fator de definição dos preços do que ao nível da definição dos custos de produção. A perseguição dos atributos locacionais assume grande importância à medida que exerce significativa influência como fator de diferenciação do valor de uso das mercadorias produzidas.

Corrêa (1986) aborda na questão das amenidades urbanas para falar sobre a valorização de determinados espaços sobre ser beneficiado devido algum elemento natural ou construído pelo homem. A localização neste caso, deve ser considerada como um elemento importante na valorização de tais lotes. Este processo também é evidente nas áreas do Lago Igapó, pois morar próximo a tal amenidade passa, com o tempo, a ser um prestígio e acessível a poucos, pois tal amenidade gera uma valorização para o local, ocasionando um maior preço do solo urbano nesta área da cidade de Londrina.

Outra questão que se apresenta para esse setor de produção imobiliária do capital, por se tratar da produção de bens imóveis é a necessidade de acesso a novo solo a cada processo de produção de moradias, fazendo da propriedade privada da terra urbana um obstáculo à realização do capital neste ramo de atividade. O controle monopolista sobre uma condição não-reprodutível (a terra) permite que os proprietários fundiários se beneficiem de parte da mais-valia gerada no processo produtivo afirma (RIBEIRO, 2003).

Rangel (2005) fala na questão dessa produção imobiliária para fins da construção, intervindo no mercado para compor a demanda total, uma demanda especulativa que em última instância é que o que determina o comportamento do preço da terra.

Tecendo considerações críticas a respeito dos pressupostos da economia neoclássica, segundo os quais o acesso à terra urbana ocorre fundamentalmente pela via do mercado definidor dos preços - através dos mecanismos clássicos da lei da oferta e da procura, Ribeiro (2003) sustenta que, por não estar submetido à lei do valor, o preço da terra urbana não decorreria de sua oferta, mas sim da demanda representada por agentes econômicos que têm nesse bem não-produzido o suporte e a condição de realização do capital. 
Ainda que não se constitua em um bem produzido, portanto, não submetido a lei do valor, a terra urbana adquire um preço. De acordo com Ribeiro (2003) à medida que não é um bem produzido, o preço da terra urbana não pode ser regulado pela lei da oferta, já que não há lei que regule sua oferta. Nesse sentido, o preço que a terra urbana adquire decorre da procura ou da demanda capitalista por solo. É justamente a demanda variada por solo, como forma de valorização do capital, que determina uma hierarquia de preços fundiários.

“[...] Há muito que a terra se tornou, no Brasil, uma mercadoria de curso franco” disse Rangel (2005). Sem remanescências feudais que, como antes o faziam, dificultavam sua distribuição e redistribuição. Um exemplo apresentado por Rangel (2005) acerca do preço do solo urbano é o de Ipanema no Rio de Janeiro, que tem o metro quadrado de solo urbano mais caro do mundo.

Em geral, a terra tornou-se caríssima no Brasil, afirma Rangel (2005). E tal resposta a esta valorização está ligada devido à demanda de terra para fins de cultivo ou construção. Em outros termos, a questão da terra no Brasil e no presente de seu desenvolvimento, emergiu essencialmente como uma questão financeira. Por outras palavras, Rangel (2005) afirma que a terra não se redistribui ou subdivide-se, porque se tornou proibitivamente cara, e é cara não apenas por motivos convencionais - capitalização da renda diferencial I, da renda diferencial II e da renda absoluta - mais sim pelo que o autor propôs de quarta renda, isto é, a de expectativa de valorização (RANGEL, 2005, p.146).

Esta é uma renda peculiar afirma Rangel (2005), que os clássicos não estudaram e que se aplica inclusive à terra que não é utilizada, porque também ela se valoriza. Mais ainda, ela faz do título imobiliário um ativo imobiliário, como as ações e as obrigações e objetivamente para a capitalização da terra pela via da compra e venda como exige o direito.

Sendo assim, a formação dos preços da terra - bem como sua influência sobre a configuração e a ocupação do espaço da cidade de Londrina - resulta da disputa dos agentes econômicos pelo controle das condições que permitem o surgimento dos sobrelucros relacionados aos atributos locacionais do espaço urbano. A esse respeito, Ribeiro (2003) é categórico quando afirma que:

A terra urbana somente adquire um preço porque o seu uso permite aos agentes econômicos obterem ganhos extraordinários nos investimentos que realizam na cidade. O preço da terra é somente um reflexo da disputa entre os diversos capitalistas pelo controle das condições que permitem o surgimento dos sobrelucros de localização (RIBEIRO, 2003, p. 40).

Geo UERJ - Ano 12, nº. 21, v. 2, 2º semestre de 2010. www.geouerj.uerj.br/ojs ISSN 1981-9021 
A semelhança da renda fundiária diferencial obtida pelos proprietários em virtude das características físicas ou naturais dos terrenos agrícolas, o solo urbano apresenta também “qualidades” distintas como função de sua localização. Nesse sentido, a disputa dos agentes econômicos pelo fator localização, relaciona-se com as possibilidades de apropriação de sobrelucros, o que confere condições monopolistas a determinadas áreas da cidade que, por conseqüência, interferem na definição dos preços da terra.

Em linha semelhante de raciocínio, Harvey (1980) afirma que os agentes capitalistas atuantes no espaço urbano dispõem-se a pagar um preço maior (ágio) pelo terreno em função de suas condições excepcionais de acessibilidade. Trata-se de um caso indireto de renda monopolista, uma vez que o que está em questão não é a comercialização da terra propriamente dita, “[...] mas a mercadoria ou o serviço produzido por meio de seu uso" (HARVEY, 1980, p. 222).

A origem da renda auferida pelos agentes econômicos relaciona-se ao acesso diferencial que a localização dos terrenos urbanos propicia, permitindo acionar o uso dos chamados valores de uso complexos representados pela cidade, em grande parte produzida pelo Estado.

Trata-se, portanto, de uma disputa dos agentes capitalistas pelos terrenos localizados em áreas dotadas de maior quantidade de trabalho incorporado, que se materializa, por exemplo, nas obras de infraestrutura. A decisão de localizar determinado empreendimento implica em “internalizar” os efeitos úteis de aglomeração, objetivo dos agentes econômicos. Nas palavras de Ribeiro, “[...] o sentido econômico desta decisão é a busca de controle de certas condições da produção não-reprodutíveis, portanto, monopolizáveis, geradoras de sobrelucros de localização” (RIBEIRO, 2003, p. 45).

As áreas do Lago Igapó e seu entorno vem sendo produzido devido a tal dinâmica do processo do modo de produção capitalista no ramo da produção de incorporação imobiliária. Situado em localização privilegiada e com incentivos e investimentos em infraestrurura e manutenção do Estado, as incorporadoras aproveitam para vender tais espaços como únicos dotados de benfeitorias e elementos que proporcionem ao morador e usuário de tal espaço uma melhor qualidade de vida.

A dinâmica da produção do espaço urbano no Brasil e principalemnete na cidade de Londrina e no entorno do Lago Igapó realimenta um permanente processo de exclusão e 
segregação e, de forma secundária, de exploração da força de trabalho - como no tempo destinado à produção da própria casa, o que reforça a convicção do papel que deve ser exercido pelo Estado no sentido da ampliação das oportunidades de acesso aos benefícios urbanos e a promoção da justiça social.

\section{A PRODUÇÃO DO ESPAÇO PÚBLICO DO LAGO IGAPÓ EM LONDRINA-PR}

Atualmente, o estudo de espaços públicos vem sendo considerado como um tema muito discutido, estando também, na preocupação da requalificação dos espaços urbanos, principalmente com as áreas centrais e com a crescente procura por lazer e recreação, além da introdução da educação ambiental no planejamento dos centros urbanos, com a temática de parques urbanos e espaços afins assume papel central no desenvolvimento dos planos e projetos urbanos. Somente nos últimos 20 anos do século XX observa-se um interesse político crescente pela implantação e formação de parques públicos.

A cidade de Londrina-PR localiza-se ao Norte do Estado do Paraná, ocupando uma área de 116,80 km² sendo que 102,54 km é o perímetro urbano (ELY, 1994, p.10). Londrina teve sua gênese em 1929, no contexto histórico da expansão cafeeira que se deslocava de São Paulo para o norte do Paraná. Ficou incumbida a Companhia de Terras Norte do Paraná (CTNP), após ter comprado as terras do Governo do Estado em 1925 e 1927, o empreendimento da ocupação de terras e viabilização das condições necessárias para os loteamentos. Rapidamente a cidade foi sendo inserida em uma dinâmica econômico-social ligada à pequena produção mercantil que implicaria no rápido e intenso crescimento populacional, físico-territorial e também na oferta de bens e serviços a sua população.

Em toda a década de 1930 se configurou na construção da cidade, sendo que na década de 1940, por sua vez, ocorreu a estruturação da área central, que assumiu assim forte ritmo de desenvolvimento, crescendo além dos limites desenhados pela (CNTP) afirma (PASSOS, 2007, p. 63). Mas foi em 1950 que se configurou como os "anos dourados” de Londrina, quando a cidade se expandiu.

A autora referida apresenta que as casas de madeira foram substituídas por casas de alvenaria, as ruas centrais foram pavimentadas e de uma forma muito cedo já, com o evidenciar das melhorias das condições econômicas e o fortalecimento da economia Londrinense, já se apresentavam algumas áreas que poderiam ser pensadas para o embelezamento e a utilização da população da cidade de Londrina. 
De acordo com Cabreira (1992), o espaço público do Lago Igapó foi criado em 1959, a partir do represamento do Ribeirão Cambé, cujo deste Ribeirão surgiram o Igapó I, o Igapó II e o Igapó III. O objetivo principal neste represamento foi à busca da ampliação das áreas de lazer e o embelezamento paisagístico da cidade de Londrina.

O Lago Igapó de certo modo assume este papel até hoje, e não podemos aqui, deixar de elucidar sobre o processo de valorização e a concentração de empreendimentos imobiliários que vem sendo produzidos pelas incorporadoras e as principais construtoras da cidade de Londrina. Tal fenômeno ocorre devido a área ser dotada de infraestrutura e propiciar práticas esportivas e de lazer para a população. Outro elemento importante que justifica a grande valorização deste espaço é o mesmo estar próximo ao centro da cidade e também próximo ao maior centro de compras do sul do país, o “Catuaí Shopping Center”.

Observe a imagem abaixo que apresenta a divisão e as áreas do espaço público do Lago Igapó em Londrina - PR.

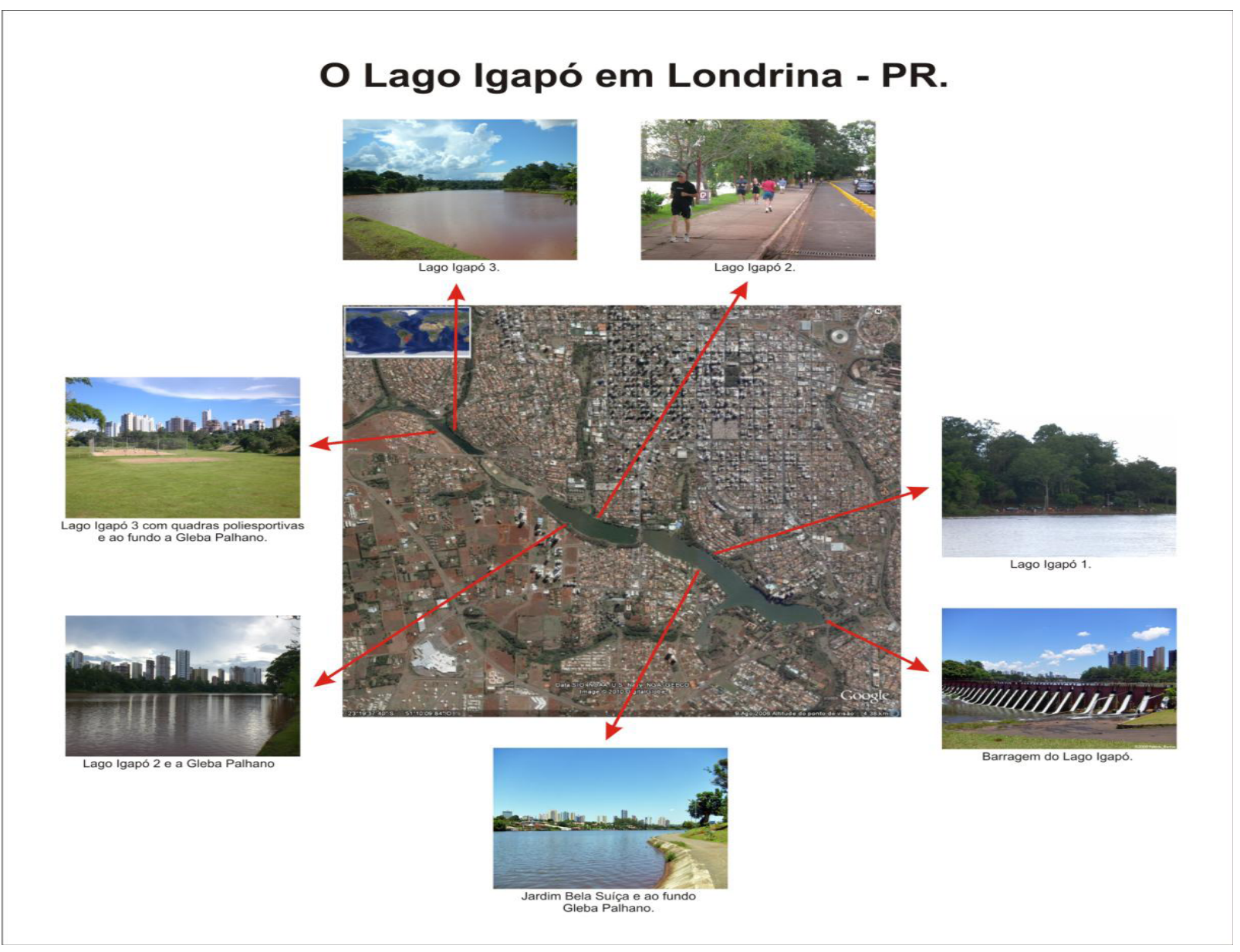

Figura 1: O Lago Igapó em Londrina - PR.

Fonte: Autor, 2010. 
Após observar os principais motivos de tal espaço ser tão valorizado e de uma dessas justificativas estarem na localização desta área, se torna evidente e claro a existência e a presença destes imóveis de grande valor comercial e destarte, parte dessa área vem se apresentando com um novo visual, como mansões, chácaras e grandes estabelecimentos comerciais para atender ao público que utiliza estes bens e serviços.

O espaço público do Lago Igapó, área esta, que atualmente atrai grande número de pessoas, devido principalmente as possibilidades de lazer e relaxamento que oferecem a população, como também o uso do espaço do lago pelo marketing que as construtoras e as incorporadoras fazem utilizando do espaço público do Lago Igapó e suas amenidades, para que com isso, tirem o maior proveito das benfeitorias e infraestruturas que o poder público local aplica neste espaço, e utilizam do elemento da beleza visual, ou seja, a "paisagem cênica” oferecida pelo Lago Igapó e comercializam seus empreendimentos, justificando que os mesmos estão localizados em áreas privilegiadas e únicas no espaço urbano londrinense.

Evidenciando que estes grandes empreendimentos imobiliários se instalaram depois do processo de requalificação urbana dessa área e no represamento do Ribeirão Cambé, qual seria a relação da apropriação de uma área pública com grandes empreendimentos privados? Qual foi/é o papel do Estado na produção, gerência deste espaço público e a relação com a produção destes empreendimentos voltados para o mercado de alto poder aquisitivo?

Algumas reflexões nos fazem observar que os órgãos públicos, fizeram inúmeras transformações e criaram nestas áreas ao redor deste lago, espaços para atrair ou despertar a atenção da população londrinense, e até mesmo, sendo considerados motivos para promoções políticas individuais. O Lago Igapó ganha a partir da década de 90 uma certa imagem para a população londrinense que observa em seu espaço determinadas funções que são apreendidas no cotidiano.

A presença de inúmeras funcionalidades são encontradas neste espaço público em questão, tanto de caráter físico-social, quanto privado individual. Esta área fica bem marcada pelo discurso da prática do lazer e do "bem-estar" junto também da questão de se analisar a “Qualidade de Vida”.

Pudemos observar em nossas análises, que o espaço público do Lago Igapó, tanto nas práticas sócioespaciais que nele vem sendo estabelecidas, como na relação entre a configuração espacial dos espaços públicos, e também na busca do entendimento das 
inúmeras formas de produção e apropriação do espaço urbano evidenciado, encontra-se nítida a ligação entre os agentes produtores públicos vinculados aos agentes produtores privados. Sejam em ações de benefícios voltados na dotação de infraestrutura, legalização de determinadas leis, como a de zoneamento, etc; tal união existe para que o processo de produção e acumulação capitalista existente no mercado imobiliário possa continuar a existir e sucessivamente com o intuito de obter os sobrelucros de tais empreendimentos.

Neste caso, no que tange a produção das áreas desse espaço público, analisamos que o processo de apropriação que se deu no espaço do Lago Igapó pelos grandes empreendimentos privados, sendo estes casas, edifícios, foram sendo produzidos com a junção de interesses e benefícios oferecidos pelo Estado, sendo estas, infraestruturas e melhorias no espaço elencado e com isso, o ganho com o processo de valorização de se produzir imóveis nos espaços do entorno do espaço público do Lago Igapó.

Portanto, tais agentes privados aproveitam para vender novos “estilos de vida”, mesmo que com isso o direito a cidade seja negado para determinadas parcelas da sociedade.

\section{CONSIDERAÇÕES FINAIS}

Neste estudo, buscou-se aclarar algumas idéias acerca da produção do espaço urbano e da cidade. Realizamos um processo de reflexão no que tange o desdobramento de estudos sobre a natureza do espaço. Tal elemento de discussão nos trouxe importantes elucubrações sobre como compreender a dinâmica da produção do espaço.

Destarte, observamos que estes espaços devem ser considerados como um sistema de objetos cada vez mais artificiais, povoados por sistemas de ações igualmente imbuídos de artificialidade, e cada vez mais tendentes a fins estranhos ao lugar e a seus habitantes.

Ao observarmos também a cidade como um produto/mercadoria apresentado por (CARLOS, 2004) podemos elucidar sobre a compreensão de como se processa as inúmeras formas de valorização do solo urbano pelas políticas de incentivo e a dotação de infraestrutura para a valorização de determinadas áreas e a busca da obtenção do sobrelucro sobre os efeitos úteis de aglomeração nos espaços urbanos.

E com isso, viemos apresentando de forma breve no decorrer do estudo, a cidade de Londrina e o Lago Igapó que se apresenta com seu entorno valorizado devido as diversas 
formas de produção, ocupação e apropriação do espaço público do Lago Igapó e suas adjacências.

Outrossim, buscou-se refletir acerca do papel desempenhado pelos Estado, sendo este um dos principais agentes produtores do espaço da cidade e fundamental para a compreensão da produção do espaço público do Lago Igapó em Londrina-PR. Tal papel designado a este agente produtor complexo e não neutro, esteve presente em todos os momentos de valorização e o mesmo, deve ser considerado grande responsável por esta valorização, devido a manutenção, incentivo e dotação de infraestrutura para melhor requalificação dos espaços do entorno do Lago Igapó, mesmo que este processo de produção do espaço urbano da cidade de Londrina e das áreas do lago ocasionassem a exclusão social e a não produção do direito a cidade e da justiça social para todos como fora pensada nos dias atuais.

Desta forma, procurou-se colaborar para o debate sobre as articulações entre a produção e alguns dos principais agentes produtores do espaço urbano. Com isso, procurou-se analisar, refletir e compreender o processo de produção e uso do solo urbano nesse espaço público onde se tem a presença de construção de residências de alto poder aquisitivo.

Portanto, buscamos analisar as diversas possibilidades e as formas de compreensão acerca da dinâmica da produção do espaço público do Lago Igapó na cidade de Londrina PR. Mas não pretendemos, de forma alguma, finalizar aqui as inúmeras possibilidades de leituras deste espaço urbano e a sua (re) produção da vida social na construção dos espaços públicos da cidade contemporânea.

\footnotetext{
' Neste caso o que é consumido não é o solo, mas sim a infraestrutura que é implantada e dotada no decorrer da produção do espaço urbano.
}

\section{REFERÊNCIAS}

ABREU, M. A. A evolução urbana do Rio de Janeiro. Ed Instituto Pereira Passos, 2006.

CABREIRA, Roberto Braz Aparecido. Uso da terra e assoreamento, Lagos IgapóLondrina/PR. 1992. ---f. Monografia (Bacharelado em Geografia) - Universidade Estadual de Londrina, Londrina.

CARLOS, A.F.A. Espaço-tempo na metrópole: a fragmentação da vida cotidiana. São Paulo: Contexto, 1988, [2001]. 

[2004]. p.123.

O espaço urbano: novos escritos sobre a cidade. São Paulo: Labur Edições, 2007

. Da "geografia abstrata" à "geografia concreta". In. Espaço e tempo: complexidade e desafios do pensar e do fazer geografia. Ademadan. 2009. P. 73-90.

CORRÊA, R. L. A rede urbana. São Paulo: Ed. Ática, 1986. O espaço urbano._São Paulo: Ática, 2002.

ELY, Deise Fabiana. Caracterização microclimática do Lago Igapó II e seu entorno, Londrina-PR. 1994. ---f. Monografia (Bacharelado em Geografia) - Universidade Estadual de Londrina, Londrina.

FRESCA, T. M. Mudanças recentes na expansão físico-territorial de Londrina. Geografia, Londrina, v. 10, n.1, p. 27-34, 2001-2002.

HARVEY, D. A justiça social e a cidade. São Paulo: Hucitec, 1980.

LEFEBVRE, H. Espaço y política: el derecho a la ciudad, II. Barcelona: Ediciones Península, 1976. p.159.

. The production of space._Oxford: Blackwell Publishing, 1991. p.454.

A revolução urbana. Belo Horizonte: Editora da UFMG, 1999. p.178.

LA production de l'espace. 4.ed.Paris: Anthropos, 2000. p.487.

MASSEY, D. B. Espaço, lugar e de gênero. Minneapolis:University of Minnesota Press (2004).

PASSOS, Viviane Rodrigues de Lima. A verticalização de Londrina: 1970/2000 - a ação dos promotores imobiliários. 2007. ---f. Dissertação (Mestrado em Geografia, Meio Ambiente e Desenvolvimento)-UEL, Londrina-PR

RANGEL, I. Obras reunidas 1914-1994. Rio de Janeiro: Contraponto, 2005.

RAZENTE, N. A ocupação urbana de Londrina. (Mestrado) Desenvolvimento urbano, UFPE, 1984.

O lago e suas áreas de lazer. Folha de Londrina, 16 dez. 1984. p. 7.

RIBEIRO, L.C.Q.; CARDOSO, A.L. Plano diretor de gestão democrática da cidade. In: RIBEIRO, L.C.Q.; CARDOSO, A.L. (Org.). Reforma urbana e gestão democrática: promessas de desafios do estatuto da cidade. Rio de Janeiro: Revan, 2003. 
SPOSITO, E.S. A vida nas cidades. São Paulo: Contexto, 1990.

SANTOS, M. A natureza do espaço. Técnica e tempo. Razão e emoção. São Paulo: Hucitec, 1996, [2002].

Enviado para publicação em outubro de 2010.

Aceito para publicação em dezembro de 2010. 